Commons about progress in the development of a package nuclear reactor for export purposes, said that recent studies have suggested that the Calder Hall type of reactor should be capable of modification to produce electricity at a competitive price from small stations of about 20-30 megawatts capacity. Other reactor systems that might be suitable for generating electricity in smaller power stations are being investigated, and two British firms have marketing rights for small power reactors of American design. British manufacturers have received a number of inquiries and are actively exploring possible markets for the types they can offer. Research is proceeding into many types of reactors; Mr. Maudling added that he understood that small reactors for civil use are not yet operating in the United States and that there is no proof of their reliability or economy.

Further questioned as to controlled thermonuclear fission, Mr. Maudling said that the experimental apparatus at Harwell known as ZETA is now operat. ing, and discharges through heavy hydrogen gas have yielded very high temperatures. Experiments are proceeding to identify the source of the accompanying neutron emission, which probably arises from thermonuclear reactions but may be due to other complex nuclear processes. Many major problems remain to be solved before the practical application of thermo nuclear reactions could be considered, and although research and development in this field are being given the highest priority, the work must be expected to remain in the research stage for some years.

\section{Responsibility for Atomic Energy Developments}

IN reply to a question in the House of Commons on November 12 as to whether, in view of the fact that responsibility for nuclear energy matters involves much detailed study of highly technical problems, he would consider transferring that responsibility from himself to a senior Minister in the House of Commons, the Prime Minister said that he considered that the existing arrangement is the most suitable at the present time. There are disadvantages, but when the various uses of nuclear energy are so much in the field that the Prime Minister of the day is bound to have them under his control, there are advantages and the system works fairly well; in the detailed work, he said, he is being greatly helped by the Paymaster-General.

\section{Instrumentation of British 'Skylark' Rockets}

A 'SKYLARK' high-altitude research rocket, fired in darkness at the Woomera rocket range on November 13, reached a height of 83 miles. It was the fourth of six proving rockets scheduled to be fired before the beginning of a joint programme of upper atmosphere research by the Royal Society and the Royal Aircraft Establishment. The first three firings having shown the performance of the rocket vehicle and its 'Raven' solid-propellant motor to be satisfactory, attention has been turned to trials of rocket. borne and ground equipment. 'Skylark No. 4', in addition to routine instrumentation, such as timing gear, telemetry sender, power supplies and Doppler transponder and microwave beacon used for tracking purposes to give velocity and position, carried equipment for four separate high-altitude measurements. First, eighteen grenades were ejected from the rocket at 3-sec. intervals at altitudes above $100,000 \mathrm{ft}$. On the ground microphones recorded the time of arrival of the sound waves, ballistic cameras recorded the positions in space of the flashes and a detector recorded the instant of each flash. The experiment, which is being made by University College, London, aims at measuring atmospheric temperatures and high-altitude wind velocities. Secondly, fourteen cartridges of 'window' (strips of fine metal foil) were released explosively in two clouds at different heights above $100,000 \mathrm{ft}$. and followed by tracking radars. The experiment, devised by the Imperial College of Science and Technology, London, is designed to measure winds at altitudes up to 50 miles. Thirdly, a section of the rocket nose was insulated from the remainder of the body to make a condenser of fixed capacity forming part of a $5 \mathrm{Mc} . / \mathrm{s}$. oscillatory circuit for measuring ionospheric electron densities, the results being telemetered to the ground. Devised by the University of Birmingham, this ingenious device will be more effective in later rockets which will penetrate farther into the ionosphere. Finally, three Pirani pressure gauges were carried in the rocket cone, one measuring ram pressure in the very tip of the nose, the other two measuring con $\theta$-wall pressures. These measurements, being made by the Royal Aircraft Establishment, onable the undisturbed ambient pressure at various altitudes to be determined.

\section{British Computer Society: Glasgow Branch}

At a meeting, held on November 11 in the Char. tered Accountants Hall, Glasgow, to inaugurate the Glasgow Branch of the British Computer Society, a committee was appointed, initially for the period until April 1958. Mr. K. D. Hendorson was elected convener and honorary secretary and the following were elected members of the Committee: Dr. D. C. Gilles, Mr. W. B. Mackay, Prof. D. C. Pack, Mr. T. B. Simpson and Mr. J. J. B. Young. The committee is arranging a series of lectures by people experienced in the application of electronic computers, the first of which will be given in December. In due course, study groups will be formed to consider various aspects of the application of computers to commercial, enginerring and scientific work. Inquiries can be addressed to Mr. K. D. Henderson, 89 Wellington Street, Glasgow, C.2.

\section{Information and Control}

Information theory has grown so rapidly and has found applications in so many fields that the new journal, Information and Control (New York: Academic Pross), can play a valuable part in centralizing research results. The editors are $X$. Brillouin (New York), C. Cherry (London) and P. Elias (Cambridge, Mass.), and there is a strong international supporting editorial board. The journal will publish work on the theories of communication, computers and automatic control, but it will also accept papers offering experimental evidence or theoretical results bearing on information theory, from related fields. In the first number, Brillouin's editorial is essentially a comment on Born's form of Occam's razor : "concepts which refer to distinctions beyond possible experience have no physical meaning and ought to be eliminated". Of the eight other items, special reference may perhaps be made to the paper by G. A. Miller and E. A. Friedman, in which, following a suggestion due to Shannon, the authors discuss various experiments in reconstructing mutilated texts. 